\title{
Intake of Cocoa Products and Risk of Type 2 Diabetes: The Multiethnic Cohort
}

\author{
Gertraud Maskarinec $^{1}$, Simone Jacobs ${ }^{2}$, Yurii Shvetsov ${ }^{1}$, Carol J. Boushey ${ }^{1}$, Veronica W. \\ Setiawan ${ }^{1}$, Laurence N. Kolonel ${ }^{1}$, Christopher A. Haiman ${ }^{3}$, and Loïc Le Marchand ${ }^{1}$ \\ ${ }^{1}$ Epidemiology Program, University of Hawaii Cancer Center, Honolulu, HI, USA \\ ${ }^{2}$ Institute of Public Health, Heidelberg University, Heidelberg, Germany \\ ${ }^{3}$ Department of Preventive Medicine, Keck School of Medicine, and Norris Comprehensive \\ Cancer Center, University of Southern California, Los Angeles, CA, USA
}

\section{Abstract}

Background/Objectives.-As cocoa products may be protective against chronic disease due to their polyphenol content, the current study determined the association of chocolate consumption and flavanol intake with type 2 diabetes (T2D) incidence in the Multiethnic Cohort (MEC) Study.

Subjects/Methods.-The analysis included 151,691 participants of Native Hawaiian, Japanese American, Latino, African American, and white ancestry with 8,487 incident T2D cases after $7.8 \pm 3.5$ years of follow-up. T2D status was based on three self-reports and confirmed by at least one of three administrative data sources. Dietary intake was assessed using a validated quantitative food frequency questionnaire and flavanols from cocoa products were estimated from self-reported consumption of chocolate candy and drinks. Cox hazard regression, adjusted for potential confounders was applied to estimate hazard ratios (HR) and 95\% confidence intervals (CI).

Results. - For chocolate candy, both the highest vs. lowest ( $\geq 10$ vs. $<1 \mathrm{~g} /$ day) consumption (HR=0.90; 95\% CI, 0.83-0.97; $\mathrm{p}_{\text {trend }}=0.01$ ) and the frequency ( $\geq 4 /$ week vs. $<1 /$ month) of intake $\left(\mathrm{HR}=0.81 ; 95 \% \mathrm{CI}, 0.72-0.91 ; \mathrm{p}_{\text {trend }}=0.0002\right)$ were inversely associated with T2D. The estimated flavanol intake from cocoa products ( $23 \mathrm{vs}$. $<1 \mathrm{mg} /$ day) also showed an inverse association with T2D risk (HR=0.93; 95\% CI, 0.88-0.99; $\left.P_{\text {trend }}=0.02\right)$. Significant interaction terms indicated that the inverse relation was limited to Japanese Americans, normal weight individuals, and to those without comorbidities.

Conclusions.-The current study confirms previous reports that participants with high intake of chocolate products and cocoa-derived flavanols experience a reduced risk of developing T2D even after controlling for sugar intake, diet quality, and other aspects of the diet.

\section{Keywords}

Type 2 diabetes; incidence; prospective cohort; cocoa products; flavanols; ethnicity; Asians

Address for Correspondence Gertraud Maskarinec, University of Hawaii Cancer Center, 701 Ilalo Street, Honolulu, HI 96813, Phone: 1-808-586-3078, gertraud@cc.hawaii.edu.

Conflicts of Interest None declared 


\section{Introduction}

Cocoa products contain substantial amounts of polyphenolic compounds, flavanols (also called flavan-3-ols), which are primarily catechins and their polymeric condensation products, i.e., procyanidins. Their biologic activity includes antioxidative properties ${ }^{1 ; 2}$ as flavan-3-ols have the ability to activate nitric oxide synthesis. ${ }^{3}$ The resulting nitric oxide may facilitate vasodilation, reduce blood pressure, ${ }^{4}$ act as an anti-inflammatory, ${ }^{5}$ and improve glucose metabolism. ${ }^{6}$ As cocoa is one of the plants with the highest flavanol concentrations, ${ }^{7}$ research into its possible protection against cardiovascular disease has increased in recent years. For example, a meta-analysis indicated lower risks of cardiovascular disease and stroke related to chocolate intake. ${ }^{8}$ To date, only four epidemiologic investigations, all large prospective cohorts, have investigated self-reported chocolate intake in relation to type 2 diabetes (T2D). These cohorts, one in Japan ${ }^{9}$ and three in the United States, ${ }^{10-12}$ collected self-reported intake by food frequency questionnaire (FFQ), with follow-up times of 5-13 years. Despite differences in exposure categories, the findings for the highest vs. the lowest intake were consistent with a risk reduction of $35 \%$ for men and 27\% for women in the Takayama Cohort Study, ${ }^{9}$ an $18 \%$ lower risk in the Atherosclerosis Risk in Communities Cohort (ARIC) Study, ${ }^{10}$ a $17 \%$ lower risk in the Physicians' Health Study (PHS)(11), and a 48\% lower risk in the Maine-Syracuse Longitudinal Study. ${ }^{12}$ In a large European cohort, estimated intakes of individual flavanols and proanthocyanidin dimers and trimers from all sources also predicted a lower T2D risk. ${ }^{13}$

T2D is a very common chronic disease around the world, ${ }^{14}$ but individuals with Pacific Islander, Asian, African American, and Latino ancestry have a particularly high disease burden. ${ }^{14 ; 15}$ Therefore, the current analysis aimed to determine the association of cocoa and chocolate intake with T2D incidence among members of the Multiethnic Cohort (MEC) which includes participants of Native Hawaiian, Japanese American, Latino, African American, and white ancestry.

\section{Methods}

\section{Study Population.}

MEC members aged 45-75 years were recruited during 1993-96 with the goal to investigate the influence of lifestyle and genetic factors on the occurrence of cancer and other chronic diseases across ethnic groups in Hawaii and California. ${ }^{16}$ The Institutional Review Boards of the University of Hawaii and the University of Southern California approved the study; return of the baseline questionnaire constituted informed consent to be part of the investigation. Of the 215,251 members, 26\% were Japanese American, 23\% white, 22\% Latino, $16 \%$ African American, $7 \%$ Native Hawaiian, and 6\% other ancestry. The response rates were $19-51 \%$; the educational profile was slightly higher than in the general population. ${ }^{16}$

\section{Questionnaire and Follow-up Data.}

At cohort entry, a 26-page, self-administered questionnaire (QX1) ${ }^{16}$ collected detailed exposure information on demographics, anthropometric characteristics, lifestyle factors, 
medical conditions, family history of cancer, reproductive history, and a diet history by means of a validated food frequency questionnaire (FFQ), which included ethnic-specific foods and was linked to a large database containing local recipes. ${ }^{17}$ Although no specific validation for cocoa-containing FFQ items was performed, the correlations for important nutrients (protein, fat, saturated fat, carbohydrates, dietary fiber, calcium, beta-carotene, vitamins $\mathrm{A}$ and $\mathrm{C}$ ) with 24-hour recalls were generally satisfactory ranging from 0.26 to 0.57). ${ }^{18}$ In 1999-2002, a 4-page follow-up questionnaire (QX2) was returned by $84 \%$ of the cohort and, during 2003-07, 50\% of MEC members completed a repeat of the full baseline questionnaire (QX3). The three questionnaires contained the same question "Has your doctor ever told you that you had diabetes?"

\section{Nutritional data.}

The intake of cocoa products was assessed from two food items in the FFQ, one asking about drinks, such as hot chocolate milk, cocoa, and ovaltine (no information on flavanols was available) and one about chocolate candy. The respondents chose from 8 frequency categories and 3 serving sizes. ${ }^{16}$ We analyzed the frequency of consumption and daily intake categories for chocolate candy and drinks separately. Candy was classified using cutoffs of 1,4 , and $10 \mathrm{~g} /$ day, which approximately represent the $50^{\text {th }}, 75^{\text {th }}$, and $90^{\text {th }}$ percentiles; drinks were categorized as none vs. any. To assess overall flavanol intake from cocoa products, we computed an estimated intake level based on Polyphenol Explorer, ${ }^{19}$ a large database containing concentrations of polyphenols in foods and drinks. We assigned a value of $20 \mathrm{mg}$ flavanols per $100 \mathrm{~g}$ of chocolate drinks. To estimate flavanol intake from chocolate candy, we assumed that $70 \%$ of the products consumed are milk chocolate and $30 \%$ dark chocolate as reported for adults 45 years and older in $2010 .^{20}$ Then we assigned $15 \mathrm{mg}$ flavanols per $100 \mathrm{~g}$ of milk chocolate and $96 \mathrm{mg}$ per $100 \mathrm{~g}$ of dark chocolate candy. Individual intake levels of flavanols were categorized into $<1,1-<3$, and $\geq 3 \mathrm{mg}$ per day (corresponding to the $50^{\text {th }}, 75^{\text {th }}$, and $90^{\text {th }}$ percentiles).

To control for the sugar content of cocoa products, we created quartiles of added sugar intake with cut-offs of 5.9, 9.5, and 15.3 teaspoons/day. Dietary Approaches to Stop Hypertension (DASH) scores, a measure of diet quality, ${ }^{21 ; 22}$ were also included. The scoring of the eight food and nutrient components contributing to the DASH score was based on intake quintiles created within the entire MEC; participants in the lowest quintile received 1 point and individuals in quintile five received 5 points. ${ }^{23}$ Red and processed meat, sugarsweetened beverages (SSBs) and sodium were reverse-coded.

\section{T2D definition.}

To optimal specificity, this analysis applied a strict definition for T2D: a self-reported plus a claims diagnosis. The percentage of self-reported T2D increased from cohort entry (12\%) to $14 \%$ in QX2 and 18\% in QX3. As administrative data sources, we had access to a Hawaii health plan linkage, ${ }^{24}$ hospital discharge data in California, ${ }^{25}$ and Medicare claims. ${ }^{26}$ Records for MEC members residing in Hawaii in 2007 were matched with diabetes care registries of two large health plans, which covered approximately $90 \%$ of the state's population. This linkage allowed incidence analyses for Hawaii. ${ }^{21 ; 24}$ When the State of California started to provide data for inpatients in general acute care hospitals in California ${ }^{25}$ 
and Medicare data became available, incidence analyses were expanded to both locations. 27;28 The 1999-2012 Medicare linkage provided chronic disease information ${ }^{29}$ on 114,309 cohort members who were fee-for-service beneficiaries; ${ }^{26}$ the information for an additional 69,061 (32\% of cohort) Medicare members with managed care plans was inadequate to determine T2D status. Based on the full dataset before exclusions and utilizing the three datasets, $83 \%$ of self-reports could be validated by health plan or hospital records. ${ }^{27 ; 28}$ The self-reports, which were not confirmed by an administrative data set, were not considered cases in the main analysis, but they were part of a sensitivity analysis with all self-reported cases as outcome.

\section{Statistical analysis.}

For the current analysis, 151,691 cohort members were retained after excluding the following observations (some overlap): 13,994 other ethnicity, 28,153 prevalent T2D at cohort entry, 9,152 invalid diet, 7,662 missing sleep information, 3,132 missing BMI, 22,045 missing physical activity, and 4 no follow-up time. The small number of participants with missing smoking status $(\mathrm{N}=1,557)$ were coded accordingly. Cox regression was applied to estimate hazard ratios (HR) and 95\% confidence intervals (CI) for T2D risk for the highest vs. the lowest intake categories. The follow-up time for cases ended at the time of first T2D diagnosis (year of QX or claim), whereas non-cases were censored in the year of death, in the year when QX2 or QX3 was answered, or, in case of non-respondents, one year before QX2 (1998) or QX3 (2002) was sent out. Similar as in prior analyses, ${ }^{30 ; 31}$ we included the following covariates: sex, age at baseline, ethnicity, education, BMI, smoking status, sleep duration, physical activity, alcohol consumption, total calories (log transformed), intake of red meat and dietary fiber (per 1,000 Kcal and log transformed), daily coffee and soda intake (servings/day), sugar intake as quartiles, and the DASH index as a measure of diet quality. The role of sex, ethnicity, age ( $<60$ vs. 260 years), BMI ( $<25 \mathrm{vs.} \geq 25 \mathrm{~kg} / \mathrm{m}^{2}$ ), and selfreported comorbidity (heart attack/stroke) as effect modifiers was assessed using stratified analyses as well as the Wald statistics. As sensitivity analyses, we repeated the main models excluding all dietary variables except total energy and also using all 10,759 self-reported T2D cases instead of 8,487 confirmed cases as outcome. The statistical code is available from the MEC study (http://www.uhcancercenter.org/research/the-multiethnic-cohort-studymec/data-sharing-mec) for researchers who meet the criteria for access to confidential data.

\section{Results}

Among the 151,691 cohort members, the mean daily intakes of chocolate candy, chocolate drinks, and estimated flavanols from these items were $5.3 \pm 12.3 \mathrm{~g}, 7.7 \pm 34.7 \mathrm{~g}$, and $3.6 \pm 8.7$ $\mathrm{mg}$, respectively. After a mean follow-up time of close to $7.8 \pm 3.5$ years, 8,487 incident cases of T2D were identified. When considering flavanols from cocoa products, $55 \%$ of participants were classified as low intake of, $20 \%$ as intermediate, and $25 \%$ as high (Table 1). Participant characteristics differed significantly by flavanol intake $(\mathrm{P}<0.0001)$; total energy, added sugar, and soda intake were higher while dietary fiber and alcohol were lower with higher flavanol consumption. Estimated daily flavanol intake differed significantly by ethnic group ( $\mathrm{p}<0.0001$ ) with means of $4.2 \mathrm{mg}$ for whites, $3.3 \mathrm{mg}$ for African Americans, $5.1 \mathrm{mg}$ for Native Hawaiians, $3.0 \mathrm{mg}$ for Japanese Americans, and $3.5 \mathrm{mg}$ for Latinos (data 
not shown); the small differences in diet quality according to DASH scores $(25,24,23,23$, 24 , respectively) were also significant. Added sugar intake was significantly lower ( $\mathrm{p}<0.0001)$ in Japanese (10.4) than whites (12.5), Latinos (14.0), African Americans (14.1), and Native Hawaiians (16.4); similarly, the obesity prevalence was lower in Japanese (6\%), whites (16\%), Latinos (22\%) than African Americans (29\%) and Native Hawaiians (33\%). Flavanol intake from cocoa products was higher $(\mathrm{p}<0.0001)$ for obese $(3.9 \mathrm{mg})$ than low, normal, and overweight participants $(3.7,3.5$, and $3.6 \mathrm{mg})$.

Results by daily intake amounts and frequency of intake showed an inverse association between chocolate candy as well as chocolate drinks and T2D risk (Table 2). The HR for consuming $\geq 10$ vs. $<1 \mathrm{~g} /$ day chocolate candy was 0.90 (95\% CI, 0.84-0.97) with a significant trend test ( $\mathrm{p}=0.01$ ), while the HR for a frequency of $\geq 4 /$ week vs. $<1 /$ month was 0.81 (95\% CI, 0.72-0.91; $\left.\mathrm{p}_{\text {trend }}=0.0002\right)$. Despite the low chocolate drink consumption, more frequent intake ( $\geq 1 /$ week vs. $\leq 1 /$ month) was related to lower T2D risk (HR=0.87; $95 \%$ CI 0.79-0.97), whereas consumers vs. non-users showed no association.

The estimated flavanol intake from cocoa products (Table 3 ) was inversely related to T2D risk $\left(P_{\text {trend }}=0.02\right)$. Those in the highest category had an HR of 0.93 (95\% CI, 0.88-0.99) as compared to the lowest intake. We did not observe effect modification by sex ( pinteraction $=0.81)$, although the HR was significant in women $(\mathrm{HR}=0.89 ; 95 \% \mathrm{CI}, 0.82$ $0.97)$ but not in men. The association was somewhat stronger in older than younger participants ( $\mathrm{HR}=0.90$ vs. 0.97 ; $\left.p_{\text {interaction }}=0.16\right)$. In ethnic-specific models ( pinteraction $=0.02)$, the association was significant in Japanese Americans $(\mathrm{HR}=0.80 ; 95 \% \mathrm{CI}$, 0.71-0.89) but not in the other ethnic groups including whites (HR=0.93; 95\% CI, 0.82 $1.05)$. Effect modification by BMI ( $\mathrm{p}_{\text {interaction }}=0.006$ ) and comorbidity $\left(\mathrm{p}_{\text {interaction }}<0.0001\right.$ ) was highly significant. The inverse association was restricted to participants with normal weight ( $\mathrm{HR}=0.83 ; 95 \% \mathrm{CI}, 0.72-0.95)$ and no comorbid condition at cohort entry (HR=0.91; 95\% CI, 0.85-0.97).

In sensitivity analyses, little change in risk estimates for flavanol intake was observed. After removing the DASH index from the model, the estimated risk for the two flavanol intake categories were 0.97 (95\% CI, 0.92-1.03) and 0.93 (95\% CI, 0.88-0.99). In models without dietary variables except total energy intake, the respective values were 0.99 (95\% CI, 0.93 1.04 ) and 0.94 (95\% CI, 0.89-0.99). When all 10,759 self-reports of T2D cases were considered cases, no associations with any measure of chocolate or flavonoid intake was detected, e.g., the HRs for the highest chocolate candy and flavanol categories were 0.99 (95\% CI, 0.92-1.05) and 1.02 (95\% CI, 0.96-1.07), respectively.

\section{Discussion}

In this large multiethnic cohort, we detected a moderately lower risk for T2D among consumers of cocoa products using different measures of exposure. The risk to develop T2D was $7 \%$ lower in those reporting the highest flavanol intake from cocoa products, $10 \%$ lower for participants with the highest consumption of chocolate candy, and 19\% lower for those reporting the highest frequency of chocolate intake. After stratification, the inverse association was restricted to women, Japanese Americans (the largest group in this study), 
individuals of normal weight, and those without a self-reported comorbidity. The estimated intake of chocolate candy in our population $(5.3 \pm 12.3 \mathrm{~g})$ was similar to reports from the National Health National Health and Nutrition Examination Survey 1999-2004. ${ }^{32}$

Although the current associations are weaker than previously reported, the findings agree with the four published cohort investigations. ${ }^{9-12}$ In the Takayama cohort with 13,540 Japanese men and women who were followed approximately 10 years, ${ }^{9}$ those who consumed $\geq 1$ piece/week as compared to never showed a an adjusted risk of 0.65 (95\% CI, $0.43-0.97$ ) among men and 0.73 (95\% CI, 0.48-1.13) among women despite a very low intake and a small number of T2D cases $(\mathrm{N}=65)$. The study also reported an inverse association for intake of coffee but not green tea, another source of catechins. The Japanese finding is in contrast to our significant association in women but not men, ${ }^{9}$ Over 13 years, the ARIC study across four states ${ }^{10}$ described risk reductions of $13 \%$ (95\% CI, $-2 \%-25 \%$ ), $34 \%(95 \% \mathrm{CI}, 18 \%-47 \%)$ and $18 \%(95 \% \mathrm{CI},-10 \%-38 \%)$ among those who ate chocolate 1-4 times/month, 2-6 times/week, and >1 time/day as compared to participants who rarely ate chocolate. During 9 years of follow-up, the Physicians' Health Study ${ }^{11}$ reported multivariable-adjusted HRs of T2D adjusted for lifestyle, clinical, and dietary risk factors (including total energy intake) of 0.93 (95\% CI, 0.79-1.09), 0.86 (95\% CI, 0.72-1.04), and 0.83 (95\% CI, 0.69-0.99) for 1-3 servings/month, 1 serving/week, and $\geq 2$ servings/week as compared to none, respectively ( $\mathrm{p}_{\text {trend }}=0.047$ ). As in the MEC analysis, the association in PHS was stronger after excluding persons with chronic conditions at cohort entry (HR= 0.77 ; 95\% CI, 0.63-0.93), and was only observed among normal weight (vs. overweight) and among younger (vs. older) physicians. Finally, in the Maine-Syracuse Longitudinal Study with 5 years of follow-up, those who never/rarely ate chocolate were more likely to have a delayed diagnosis (OR, 1.91; 95\% CI, 1.03-3.55) than those who consumed chocolate $>1 /$ week, after adjustment for cardiovascular, lifestyle and dietary factors. ${ }^{12}$

The weaker associations in the current analysis than in the four published reports may be a result of the more extensive adjustment for known T2D risk factors, including dietary fiber, red meat, coffee, soda and sugar intake, diet quality, and sleep duration in addition to the more common covariates of total energy and alcohol intake, although removing the diet variables did not substantially modify our findings. Only the ARIC study ${ }^{10}$ included a measure of diet quality, while dietary variables in the other studies were limited to total energy, alcohol, and grains. ${ }^{11 ; 12}$ The strong inverse association among Japanese Americans, which is supported by the Takayama study ${ }^{9}$ but not present in the other ethnic groups, is a challenging issue. The greater power in this largest subgroup may have driven this finding, but the low intake of added sugar, the low obesity prevalence, and the high T2D incidence despite low body weight ${ }^{24}$ may have also contributed to the significant findings in Japanese Americans. As seen in the subgroup analyses by BMI and comorbidity, flavanol intake from cocoa products showed a stronger association in individuals with normal BMI and without comorbid conditions.

Strengths of the current analysis include the large sample size, the validated FFQ, the high incidence of T2D, and the highly specific diagnosis of T2D based on self-reports and administrative data as demonstrated by the lack of an association when all T2D self-reports instead of confirmed cases only were used. On the other hand, the lack of validation for 
cocoa products in the FFQ may have introduced misclassification bias. ${ }^{18}$ A limitation of this and the four published cohort studies ${ }^{9-12}$ is the absence of detailed information about different types (and brands) of chocolate, i.e., milk (15 mg) vs. dark chocolate (96 mg), an important determinant of flavanol intake. ${ }^{1}$ Also, without the inclusion of other food sources of flavanols, it is not possible to examine potential differences due to cocoa-derived flavanols and total flavanol intake. However, an analysis from the European Prospective Investigation into Cancer and Nutrition (EPIC) cohort, with 12,043 incident T2D cases, confirmed significant inverse trends between consumption of individual flavan-3-ol monomers and proanthocyanidin dimers and trimers from all food sources (primarily tea, fruit, coffee, beer, cider, wine, chocolate) and T2D risk. ${ }^{13}$ In addition to the caution necessary in interpreting data from observational studies, residual confounding from other factors has to be considered. It is clear that the high energy density of commonly consumed chocolate products $(2100 \mathrm{~kJ}(500 \mathrm{kcal}) / 100 \mathrm{~g})$ may lead to weight gain due to high energy intake among individuals with elevated candy consumption. ${ }^{33}$ As to the amount of flavanols needed for beneficial health effects, a significant decrease in blood pressure was observed in a trial with $6.3 \mathrm{~g}(30 \mathrm{kcal})$ per day of dark chocolate equivalent to $30 \mathrm{mg}$ of polyphenols. ${ }^{34}$

Potential mechanisms for a protective association between cocoa products and T2D development ${ }^{2}$ include improved insulin sensitivity, as shown in short-term trials with highpolyphenol dark chocolate. ${ }^{35}$ One meta-analysis of clinical trials suggested that insulin resistance as assessed by HOMA-IR was improved significantly by chocolate or cocoa intake due to reductions in serum insulin concentrations. ${ }^{36}$ Another meta-analysis found that relevant biomarkers decreased in randomized clinical trials when cocoa flavanols were compared to a placebo. ${ }^{37}$ As knowledge about the gut microbiome in health has increased, an influence of procyanidins on the composition of bacteria populations appears likely. ${ }^{38 ; 39}$ For example, in pigs supplemented with cocoa powder, the relative abundance of Lactobacillus and Bifidobacterium species was increased. ${ }^{40}$ In an intervention with healthy volunteers, in addition to higher catechin and lower CRP levels during the high-cocoa flavan-3-ol intervention period, the composition of the gut microbiome was modified significantly. ${ }^{38}$

The current study within the MEC confirms the findings of four previous cohorts showing that participants with higher chocolate consumption and higher flavanol intake from cocoa products experience a lower risk of developing T2D, even after controlling for diet quality, sugar intake, and other dietary components. With flavanols as a summary measure of exposure, the protective association of cocoa products appeared stronger in women and Japanese Americans and was limited to normal weight individuals and those without comorbidity. In future research, a better assessment of different types of chocolate, i.e., white, milk, dark, would allow a more accurate assessment of flavanol intake and improved classification of exposure to elucidate the role of flavanols in chronic disease development.

\section{Acknowledgments}

This work was supported by the grants from the National Institutes of Health (R37CA54281, U01CA164973, P30CA71789, and R21DK073816). A postdoctoral training grant from the Deutsche Forschungsgemeinschaft (JA 2564/1-1) supported SJ. 
Sources of Financial Support: This work was supported by the grants from the National Institutes of Health (R37CA54281, UM1CA164973, and R21 DK073816)

\section{References}

(1). Gu L, House SE, Wu X, Ou B, Prior RL. Procyanidin and catechin contents and antioxidant capacity of cocoa and chocolate products. J Agric Food Chem 2006; 54: 4057-4061. [PubMed: 16719534]

(2). Strat KM, Rowley TJ, Smithson AT, Tessem JS, Hulver MW, Liu D et al. Mechanisms by which cocoa flavanols improve metabolic syndrome and related disorders. J Nutr Biochem 2016; 35 : 1 21. [PubMed: 27560446]

(3). Grassi D, Desideri G, Ferri C. Protective effects of dark chocolate on endothelial function and diabetes. Curr Opin Clin Nutr Metab Care 2013; 16: 662-668. [PubMed: 24100673]

(4). Ried K, Sullivan TR, Fakler P, Frank OR, Stocks NP. Effect of cocoa on blood pressure. Cochrane Database Syst Rev 2012; 8: CD008893.

(5). di Giuseppe R, Di Castelnuovo A, Centritto F, Zito F, De Curtis A, Costanzo S et al. Regular consumption of dark chocolate is associated with low serum concentrations of C-reactive protein in a healthy Italian population. J Nutr 2008; 138: 1939-1945. [PubMed: 18806104]

(6). Grassi D, Desideri G, Mai F, Martella L, De FM, Soddu D et al. Cocoa, glucose tolerance and insulin signalling: the cardiometabolic protection. J Agric Food Chem 2015.

(7). Perez-Jimenez J, Neveu V, Vos F, Scalbert A. Identification of the 100 richest dietary sources of polyphenols: an application of the Phenol-Explorer database. Eur J Clin Nutr 2010; 64 Suppl 3: S112-S120. [PubMed: 21045839]

(8). Buitrago-Lopez A, Sanderson J, Johnson L, Warnakula S, Wood A, Di AE et al. Chocolate consumption and cardiometabolic disorders: systematic review and meta-analysis. BMJ 2011; 343: d4488. [PubMed: 21875885]

(9). Oba S, Nagata C, Nakamura K, Fujii K, Kawachi T, Takatsuka N et al. Consumption of coffee, green tea, oolong tea, black tea, chocolate snacks and the caffeine content in relation to risk of diabetes in Japanese men and women. Br J Nutr 2010; 103: 453-459. [PubMed: 19818197]

(10). Greenberg JA. Chocolate intake and diabetes risk. Clin Nutr 2015; 34: 129-133. [PubMed: 24582922]

(11). Matsumoto C, Petrone AB, Sesso HD, Gaziano JM, Djousse L. Chocolate consumption and risk of diabetes mellitus in the Physicians' Health Study. Am J Clin Nutr 2015; 101: 362-367. [PubMed: 25646334]

(12). Crichton GE, Elias MF, Dearborn P, Robbins M. Habitual chocolate intake and type 2 diabetes mellitus in the Maine-Syracuse Longitudinal Study: (1975-2010): Prospective observations. Appetite 2017; 108: 263-269. [PubMed: 27725277]

(13). Zamora-Ros R, Forouhi NG, Sharp SJ, Gonzalez CA, Buijsse B, Guevara M et al. Dietary intakes of individual flavanols and flavonols are inversely associated with incident type 2 diabetes in European populations. J Nutr 2014; 144: 335-343. [PubMed: 24368432]

(14). International Diabetes Federation. IDF Diabetes Atlas. http://www.diabetesatlas.org/ 2015 IDF, Bruxelles, Belgium 10-7-2016.

(15). Maskarinec G, Grandinetti A, Matsuura G, Sharma S, Mau M, Henderson BE et al. Diabetes prevalence and body mass index differ by ethnicity: the Multiethnic Cohort. Ethn Dis 2009; 19: 49-55. [PubMed: 19341163]

(16). Kolonel LN, Henderson BE, Hankin JH, Nomura AMY, Wilkens LR, Pike MC et al. A multiethnic cohort in Hawaii and Los Angeles: baseline characteristics. Am J Epidemiol 2000; 151: 346-357. [PubMed: 10695593]

(17). Murphy SP. Unique nutrition support for research at the Cancer Research Center of Hawaii. Hawaii Med J 2002; 61: 15, 17. [PubMed: 11868199]

(18). Stram DO, Hankin JH, Wilkens LR, Henderson B, Kolonel LN. Calibration of the dietary questionnaire for a multiethnic cohort in Hawaii and Los Angeles. Am J Epidemiol 2000; 151: 358-370. [PubMed: 10695594] 
(19). Neveu V, Perez-Jimenez J, Vos F, Crespy V, du CL, Mennen L et al. Phenol-Explorer: an online comprehensive database on polyphenol contents in foods. Database (Oxford) 2010; 2010: bap024. [PubMed: 20428313]

(20). Statistica. Milk and dark chocolate consumption in the United States in 2010. www.statista.com/ statistics/238730/milk-and-dark-chocolate-consumption-in-the-us-by-age-group/ 2017 7-2-2017.

(21). Jacobs S, Harmon BE, Boushey CJ, Morimoto Y, Wilkens LR, Le ML et al. A priori-defined diet quality indexes and risk of type 2 diabetes: the Multiethnic Cohort. Diabetologia 2015; 58: 98 112. [PubMed: 25319012]

(22). Harmon BE, Boushey CJ, Shvetsov YB, Ettienne R, Reedy J, Wilkens LR et al. Associations of key diet-quality indexes with mortality in the Multiethnic Cohort: the Dietary Patterns Methods Project. Am J Clin Nutr 2015; 101: 587-597. [PubMed: 25733644]

(23). Fung TT, Chiuve SE, McCullough ML, Rexrode KM, Logroscino G, Hu FB. Adherence to a DASH-style diet and risk of coronary heart disease and stroke in women. Arch Intern Med 2008; 168: 713-720. [PubMed: 18413553]

(24). Maskarinec G, Erber E, Grandinetti A, Verheus M, Oum R, Hopping BN et al. Diabetes incidence based on linkages with health plans: the multiethnic cohort. Diabetes 2009; 58: 1732 1738. [PubMed: 19258435]

(25). State of California Office of Statewide Health Planning \& Development. Health Care Information Division - Patient Discharge Data. http://www.oshpd.ca.gov/HID/Products/PatDischargeData/ PublicDataSet/index.html 2015 7-9-2015.

(26). Setiawan VW, Virnig BA, Porcel J, Henderson BE, Le ML, Wilkens LR et al. Linking data from the Multiethnic Cohort Study to Medicare data: linkage results and application to chronic disease research. Am J Epidemiol 2015; 181: 917-919. [PubMed: 25841869]

(27). Jacobs S, Boushey CJ, Franke AA, Shvetsov YB, Monroe KR, Haiman CA et al. A priori-defined diet quality indices, biomarkers and risk for type 2 diabetes in five ethnic groups: the Multiethnic Cohort. Br J Nutr 2017; 118: 312-320. [PubMed: 28875870]

(28). Maskarinec G, Jacobs S, Amshoff Y, Setiawan VW, Shvetsov YB, Franke AA et al. Sleep duration and incidence of type 2 diabetes: the Multiethnic Cohort. Sleep Health 2018; 4: 27-32. [PubMed: 29332675]

(29). Chronic Condition Data Warehouse. Condition Categories. https://www.ccwdata.org/web/guest/ condition-categories 9-1-2014. 7-3-2015.

(30). Steinbrecher A, Morimoto Y, Heak S, Ollberding NJ, Geller KS, Grandinetti A et al. The preventable proportion of type 2 diabetes by ethnicity: the multiethnic cohort. Ann Epidemiol 2011; 21: 526-535. [PubMed: 21497517]

(31). Doo T, Morimoto Y, Steinbrecher A, Kolonel LN, Maskarinec G. Coffee intake and risk of type 2 diabetes: the Multiethnic Cohort. Public Health Nutr 2013; 1-9.

(32). O’Neil CE, Fulgoni VL III, Nicklas TA. Candy consumption was not associated with body weight measures, risk factors for cardiovascular disease, or metabolic syndrome in US adults: NHANES 1999-2004. Nutr Res 2011; 31: 122-130. [PubMed: 21419316]

(33). Greenberg JA, Manson JE, Buijsse B, Wang L, Allison MA, Neuhouser ML et al. Chocolatecandy consumption and 3-year weight gain among postmenopausal U.S. women. Obesity (Silver Spring) 2015; 23: 677-683. [PubMed: 25644711]

(34). Taubert D, Roesen R, Lehmann C, Jung N, Schomig E. Effects of low habitual cocoa intake on blood pressure and bioactive nitric oxide: a randomized controlled trial. JAMA 2007; 298: 49-60. [PubMed: 17609490]

(35). Grassi D, Desideri G, Necozione S, Lippi C, Casale R, Properzi G et al. Blood pressure is reduced and insulin sensitivity increased in glucose-intolerant, hypertensive subjects after 15 days of consuming high-polyphenol dark chocolate. J Nutr 2008; 138: 1671-1676. [PubMed: 18716168]

(36). Hooper L, Kay C, Abdelhamid A, Kroon PA, Cohn JS, Rimm EB et al. Effects of chocolate, cocoa, and flavan-3-ols on cardiovascular health: a systematic review and meta-analysis of randomized trials. Am J Clin Nutr 2012; 95: 740-751. [PubMed: 22301923] 
(37). Lin X, Zhang I, Li A, Manson JE, Sesso HD, Wang L et al. Cocoa Flavanol Intake and Biomarkers for Cardiometabolic Health: A Systematic Review and Meta-Analysis of Randomized Controlled Trials. J Nutr 2016; 146: 2325-2333. [PubMed: 27683874]

(38). Tzounis X, Rodriguez-Mateos A, Vulevic J, Gibson GR, Kwik-Uribe C, Spencer JP. Prebiotic evaluation of cocoa-derived flavanols in healthy humans by using a randomized, controlled, double-blind, crossover intervention study. Am J Clin Nutr 2011; 93: 62-72. [PubMed: 21068351]

(39). Etxeberria U, Fernandez-Quintela A, Milagro FI, Aguirre L, Martinez JA, Portillo MP. Impact of polyphenols and polyphenol-rich dietary sources on gut microbiota composition. J Agric Food Chem 2013; 61: 9517-9533. [PubMed: 24033291]

(40). Jang S, Sun J, Chen P, Lakshman S, Molokin A, Harnly JM et al. Flavanol-Enriched Cocoa Powder Alters the Intestinal Microbiota, Tissue and Fluid Metabolite Profiles, and Intestinal Gene Expression in Pigs. J Nutr 2016; 146: 673-680. [PubMed: 26936136] 
Table 1.

Characteristics of the Study Population, Multiethnic Cohort, 1993-2010

\begin{tabular}{|c|c|c|c|c|}
\hline \multirow{2}{*}{ Characteristic } & \multirow{2}{*}{ Category } & \multicolumn{3}{|c|}{ Estimated Flavanol Intake (mg/day) ${ }^{d}$} \\
\hline & & $<1$ & $1-<3$ & $\geq \mathbf{3}$ \\
\hline Participants & Number & $83,692(55 \%)$ & $30,671(20 \%)$ & $37,328(25 \%)$ \\
\hline Type 2 diabetes cases & Number & $4,613(55 \%)$ & $1,819(21 \%)$ & $2,055(24 \%)$ \\
\hline Age at cohort entry ${ }^{a}$ & Years & $59.7(8.7)$ & $58.2(8.8)$ & $58.9(9.1)$ \\
\hline Age at diabetes diagnosis ${ }^{a}$ & Years & $64.0(8.0)$ & $62.3(8.0)$ & $62.6(8.4)$ \\
\hline Follow-up time ${ }^{a}$ & Years & $7.8(3.4)$ & $8.0(3.5)$ & $7.8(3.5)$ \\
\hline Energy intake ${ }^{a}$ & $\mathrm{kcal} /$ day & $1,943(902)$ & 2,167 (955) & $2,560(1,169)$ \\
\hline Red meat $^{a}$ & $\mathrm{~g} / 1000 \mathrm{kcal} /$ day & $25.2(16.6)$ & $28.3(15.8)$ & $26.4(15.0)$ \\
\hline Dietary fiber ${ }^{a}$ & $\mathrm{~g} / 1000 \mathrm{kcal} /$ day & $12.3(4.6)$ & $11.1(3.9)$ & $10.7(3.6)$ \\
\hline Added sugar $^{a}$ & teaspoons/day & $9.8(9.6)$ & $12.8(11.0)$ & $19.1(15.0)$ \\
\hline $\mathrm{DASH}^{c}$ & Scores & $24.0(4.5)$ & $23.5(4.4)$ & $24.3(4.2)$ \\
\hline \multirow[t]{2}{*}{$\operatorname{Sex}(\%)$} & Male & 45.1 & 45.7 & 46.4 \\
\hline & Female & 54.9 & 54.3 & 53.6 \\
\hline \multirow[t]{5}{*}{ Ethnicity (\%) } & White & 25.0 & 28.7 & 32.0 \\
\hline & African American & 15.5 & 15.5 & 14.3 \\
\hline & Native Hawaiian & 5.8 & 7.9 & 9.6 \\
\hline & Japanese American & 32.4 & 29.3 & 25.6 \\
\hline & Latino & 21.4 & 18.5 & 18.6 \\
\hline \multirow[t]{3}{*}{ Education (\%) } & $<12$ years & 41.6 & 38.5 & 40.3 \\
\hline & $13-15$ years & 30.1 & 31.6 & 30.2 \\
\hline & $\geq 16$ years & 28.2 & 29.9 & 29.5 \\
\hline \multirow[t]{4}{*}{ BMI (\%) } & $<18.5 \mathrm{~kg} / \mathrm{m}^{2}$ & 2.1 & 1.3 & 2.1 \\
\hline & $\geq 18.5-<25 \mathrm{~kg} / \mathrm{m}^{2}$ & 43.7 & 39.7 & 41.5 \\
\hline & $\geq 25-<30 \mathrm{~kg} / \mathrm{m}^{2}$ & 38.0 & 39.4 & 37.5 \\
\hline & $30 \mathrm{~kg} / \mathrm{m}^{2}$ & 16.2 & 19.6 & 18.9 \\
\hline \multirow[t]{3}{*}{ Smoking status (\%) } & Never & 44.0 & 42.9 & 44.6 \\
\hline & Past & 39.7 & 39.7 & 36.8 \\
\hline & Current & 15.2 & 16.6 & 17.7 \\
\hline \multirow[t]{3}{*}{ Alcohol intake, drinks (\%) } & $<1 \mathrm{mo}$ & 51.0 & 49.8 & 52.4 \\
\hline & $\geq 1 /$ mo-<1/day & 27.5 & 31.5 & 29.8 \\
\hline & $\geq 1 /$ day & 20.5 & 18.3 & 17.3 \\
\hline \multirow[t]{2}{*}{ Physical activity (\%) } & $<30 \mathrm{~min} /$ day & 37.2 & 35.0 & 35.1 \\
\hline & $\geq 30 \mathrm{~min} /$ day & 62.8 & 65.0 & 64.9 \\
\hline \multirow[t]{3}{*}{ Coffee intake in cups $(\%)$} & $0-<1 /$ day & 34.8 & 34.6 & 38.7 \\
\hline & $1 /$ day & 32.4 & 30.4 & 27.9 \\
\hline & 2/day & 23.9 & 25.1 & 23.0 \\
\hline
\end{tabular}




\begin{tabular}{lcccc}
\hline \multirow{2}{*}{ Characteristic } & Category & \multicolumn{3}{c}{ Estimated Flavanol Intake (mg/day) ${ }^{\boldsymbol{d}}$} \\
& & $<\mathbf{1}$ & $\mathbf{1 - < 3}$ & $\boldsymbol{\mathbf { 3 }}$ \\
\hline \multirow{3}{*}{ Soda intake (\%) } & $\geq 3 /$ day & 8.9 & 10.0 & 10.4 \\
& None & 44.6 & 33.7 & 30.8 \\
& $1 /$ week & 31.3 & 33.0 & 30.3 \\
& $\geq 2 /$ week & 24.1 & 33.3 & 38.9 \\
& Yes & 8.6 & 7.3 & 7.8 \\
\hline
\end{tabular}

${ }^{a}$ Values represent means and standard deviations

$b_{\text {Heart attack or stroke }}$

${ }^{c}$ Dietary Approaches to Stop Hypertension (DASH) scores are based on 8 food and nutrient components; 1 point is assigned for the lowest quintile and individuals in quintile five received 5 points.

$d_{\mathrm{p}}$

${ }_{\mathrm{p}}<0.01$ across flavanol intake categories for all study characteristics 
Table 2.

Intake of Chocolate Candy/Drink and Incidence of Type 2 Diabetes Multiethnic Cohort, 1993-2010

\begin{tabular}{|c|c|c|c|c|c|c|c|}
\hline Exposure variable & Category & Participants & T2D cases & HR & $95 \%$ & CI & $\mathbf{p}_{\text {trend }} b$ \\
\hline \multirow[t]{4}{*}{ Chocolate candy, g/day } & $<1$ & 71,949 & 3,954 & 1.00 & & & \\
\hline & $1-<4$ & 27,295 & 1,563 & 0.97 & 0.91 & 1.03 & \\
\hline & $4-<10$ & 31,180 & 1,877 & 0.97 & 0.91 & 1.02 & \\
\hline & $\geq 10$ & 21,267 & 1,093 & 0.90 & 0.84 & 0.97 & 0.01 \\
\hline \multirow[t]{4}{*}{ Frequency of chocolate intake } & $<1 /$ month & 50,273 & 2,797 & 1.00 & & & \\
\hline & $1-3 /$ month & 62,665 & 3,639 & 0.97 & 0.92 & 1.02 & \\
\hline & $1-3 /$ week & 26,977 & 1,479 & 0.92 & 0.86 & 0.98 & \\
\hline & $\geq 4 /$ week & 8,469 & 388 & 0.81 & 0.72 & 0.91 & 0.0002 \\
\hline \multirow[t]{2}{*}{ Chocolate drink intake } & None & 123,026 & 6,843 & 1.00 & & & \\
\hline & Consumer & 28,665 & 1,644 & 0.96 & 0.91 & 1.02 & 0.20 \\
\hline \multirow[t]{3}{*}{ Frequency of chocolate drink intake } & $<1 /$ month & 118,532 & 6,583 & 1.00 & & & \\
\hline & $1-3 /$ month & 20,213 & 1,222 & 0.99 & 0.93 & 1.06 & \\
\hline & $\geq 1 /$ week & 8,383 & 419 & 0.87 & 0.79 & 0.97 & 0.04 \\
\hline
\end{tabular}

a Hazard ratios (HR) and 95\% confidence intervals (CI) obtained from Cox regression, stratified by for age at cohort entry, and adjusted for sex, ethnicity, BMI, smoking status, education, sleep duration, physical activity, DASH index, intake of total energy, alcohol, coffee, soda, added sugar, red meat, and dietary fiber.

$b$

p-value obtained from Cox regression using category values as continuous variable 
Table 3.

Estimated Flavanol Intake from Cocoa Products and Incidence of Type 2 Diabetes Multiethnic Cohort, $1993-2010^{a}$

\begin{tabular}{|c|c|c|c|c|c|c|c|c|c|c|}
\hline \multirow{4}{*}{$\begin{array}{l}\text { Variable } \\
\text { All }\end{array}$} & \multirow{4}{*}{ Category } & \multirow{4}{*}{$\begin{array}{c}\begin{array}{c}\text { Cases/ } \\
\text { Population }\end{array} \\
8,487 / 151,691\end{array}$} & \multicolumn{7}{|c|}{ Estimated Flavanol Intake (mg/day) } & \multirow{4}{*}{$p_{\text {Interaction }}$} \\
\hline & & & \multirow{3}{*}{$\begin{array}{c}<1 \\
\text { HR } \\
1.00\end{array}$} & \multirow{3}{*}{$\frac{\text { HR }}{0.97}$} & \multicolumn{2}{|l|}{$1-<3$} & \multicolumn{3}{|c|}{$\geq \mathbf{3}$} & \\
\hline & & & & & $95 \%$ & CI & HR & 95 & CI & \\
\hline & & & & & 0.92 & 1.03 & 0.93 & 0.88 & 0.99 & \\
\hline \multirow[t]{2}{*}{ Sex } & Men & $4,204 / 69,097$ & 1.00 & 0.98 & 0.90 & 1.06 & 0.98 & 0.90 & 1.06 & 0.81 \\
\hline & Women & $4,283 / 82,594$ & 1.00 & 0.97 & 0.90 & 1.05 & 0.89 & 0.82 & 0.97 & \\
\hline \multirow[t]{2}{*}{ Age } & $<60$ years & $4,436 / 77,240$ & 1.00 & 0.98 & 0.91 & 1.06 & 0.97 & 0.89 & 1.05 & 0.16 \\
\hline & 260 years & $4,051 / 74,451$ & 1.00 & 0.96 & 0.88 & 1.04 & 0.90 & 0.82 & 0.98 & \\
\hline \multirow[t]{5}{*}{ Ethnicity } & White & $1,679 / 41,681$ & 1.00 & 0.90 & 0.79 & 1.02 & 0.93 & 0.82 & 1.05 & 0.02 \\
\hline & African Am. & $1,242 / 23,069$ & 1.00 & 1.11 & 0.96 & 1.28 & 1.05 & 0.90 & 1.22 & \\
\hline & Nat. Hawaiian & $908 / 10,813$ & 1.00 & 1.00 & 0.84 & 1.19 & 1.01 & 0.85 & 1.19 & \\
\hline & Japanese Am. & $2,779 / 45,628$ & 1.00 & 0.99 & 0.90 & 1.09 & 0.80 & 0.71 & 0.89 & \\
\hline & Latino & $1,879 / 30,500$ & 1.00 & 0.91 & 0.81 & 1.04 & 1.01 & 0.89 & 1.14 & \\
\hline \multirow[t]{2}{*}{ BMI $\left(\mathrm{kg} / \mathrm{m}^{2}\right)$} & $<25$ & $1,593 / 67,190$ & 1.00 & 0.89 & 0.78 & 1.02 & 0.83 & 0.72 & 0.95 & 0.006 \\
\hline & $\geq 25$ & $6,894 / 84,501$ & 1.00 & 1.00 & 0.94 & 1.06 & 0.96 & 0.90 & 1.02 & \\
\hline \multirow[t]{2}{*}{ Comorbidity $^{c}$} & No & $7,514 / 139,197$ & 1.00 & 0.96 & 0.90 & 1.02 & 0.91 & 0.85 & 0.97 & $<0.0001$ \\
\hline & Yes & $970 / 12,381$ & 1.00 & 1.14 & 0.97 & 1.35 & 1.19 & 1.00 & 1.42 & \\
\hline
\end{tabular}

${ }^{a}$ Hazard ratios (HR) and 95\% CIs were obtained by Cox regression stratified by age at cohort entry, adjusted sex, ethnicity, BMI, smoking status, education, sleep duration, physical activity, DASH index, intake of total energy, alcohol, coffee, soda, added sugar, red meat, and dietary fiber.

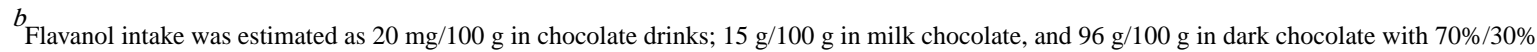
milk vs. dark chocolate

${ }^{c}$ Heart attack or stroke 